\title{
Knowledge, attitude, and practice towards Hepatitis B infection among nurses and midwives in two maternity hospitals in Khartoum, Sudan
}

Sanaa Mohammed-elbager Mahmoud Mursy and Sagad Omer Obeid Mohamed*i(

\begin{abstract}
Background: Hepatitis B virus (HBV) infection creates a global health burden with significant morbidity and mortality. Healthcare workers, including nurses and midwives, are at higher risk of acquiring the disease. While health-related behaviours are affected by different aspects of knowledge, attitude, and practices (KAP), there are few studies examining the KAP level of healthcare workers towards HBV infection in Sudan. The purpose of this study was to examine the KAP level of nurses and midwives towards HBV virus infection in Khartoum, Sudan.

Methods: A cross-sectional descriptive hospital-based study was conducted in two public maternity hospitals (Saudi and Saad Abul-Eleella hospitals) in Khartoum state of, Sudan. A pre-tested structured questionnaire was constructed and implemented to examine KAP towards HBV infection. Statistical Package for Social Sciences (SPSS) version of 21 was utilized to conduct statistical analysis and examine the data at hand. Chi-square test was used implemented to determine the relationship between categorical variables.

Results: A total of 110 nurses and midwives from the both hospitals participated in this study. More than half of the respondents (58.2\%) had an average level of knowledge, two-third of the respondents had a safe practice, and the majority of the respondents had a favourable attitude towards HBV preventive measures. Approximately half of the participants (51.8\%) had a history of needle stick injuries. Half of the participants had inaccurate concepts about post exposure prophylaxis to HBV infection, while more than half of the nurses and midwives didn't complete the vaccination schedule for HBV.

Conclusion: Most of the nurses and midwives in Saudi and Saad Abul-Eleella hospitals were aware of HBV infection. However, a significant proportion of the participants lack the requisite knowledge about post exposure management. The study revealed a low level of HBV vaccination coverage rate and a high rate of needle stick injuries. Further strategies for preventing workplace exposure, training programs on HBV infection, including post exposure prophylaxis, and increasing vaccination coverage rate of all HCWS are highly recommended.
\end{abstract}

Keywords: Hepatitis B, Sudan, KAP

* Correspondence: s.oom123@yahoo.com

Faculty of Medicine, University of Khartoum, Qasr Street, P.O. Box 11111,

Khartoum, Sudan

(c) The Author(s). 2019 Open Access This article is distributed under the terms of the Creative Commons Attribution 4.0 International License (http://creativecommons.org/licenses/by/4.0/), which permits unrestricted use, distribution, and reproduction in any medium, provided you give appropriate credit to the original author(s) and the source, provide a link to the Creative Commons license, and indicate if changes were made. The Creative Commons Public Domain Dedication waiver (http://creativecommons.org/publicdomain/zero/1.0/) applies to the data made available in this article, unless otherwise stated. 


\section{Background}

Hepatitis B virus (HBV) infection creates a global health burden with significant morbidity and mortality from both acute infection and chronic complications, including chronic hepatitis, cirrhosis, and hepatocellular carcinoma [1-5]. The number of patients with positive hepatitis $B$ surface antigen (HBsAg) worldwide increased from 223 million in 1990 to 240 million in 2005 [6]. Several studies have provided estimates of the prevalence of HBV infection among several Sudanese populations [3, 7-9]. A recent systematic review and meta-analysis including 14 studies with 5848 participants have been conducted in Sudan, revealing that $\mathrm{HBV}$ seroprevalence rates ranged from 5.1 to $26.8 \%$ with an overall pooled prevalence of 12.1\%. According to study findings, Khartoum State had the highest prevalence of HBV infection in Sudan with a proportion of $12.7 \%$ [1]. Likewise, this rate is comparable to other African countries such as Burundi (15.6\%), Central African Republic (14\%), while it is higher than Nigeria (5\%) and Ethiopia (7\%) [2].

Risk factors for HBV infection include transfusion of infectious blood and mother to child transmission (MTCT) of the virus [2, 3]. Pregnancy is well tolerated by women with chronic hepatitis B infection, but postpartum reconstitution of the immune system is associated with an elevated level of liver enzymes and active hepatitis [10]. MTCT of HBV can occur at three stages of pregnancy: intrauterine, intrapartum or postpartum, and the risk for MTCT of HBV increases with high maternal viral load, positive $\mathrm{HBeAg}$ status, preterm labour, prolonged labour and failure of immunoprophylaxis in siblings $[10,11]$. The current standard of care for the prevention of MTCT of HBV infection includes an active and passive immunoprophylaxis with HBV immunoglobulin and vaccination administered immediately after birth to neonates of HBsAg positive mothers, and referral of mothers to hepatology clinics for assessment and follow up $[11,12]$.

Healthcare workers (HCWs), including nurses and midwives, had a higher risk of exposure and acquired the disease if the personal protective measures were not appropriately used $[13,14]$. Onwards HBV transmission could be related to lack of awareness about HBV prevalence and occupational safety measures such as vaccination against HBV, post-exposure prophylaxis (PEP), training and adopting safer working practices $[1,9,10]$. Handling sharps and needle stick injuries (NSI) represent major risks for unvaccinated HCWSs and involve potential exposure to several pathogens, including $\operatorname{HBV}[14,15]$.

In the study setting, nurses and midwives have an important role in the care of people with HBV infection. They provide support during treatment and education about the nature of the disease, diagnosis, prevention, and timely administration of immunoglobulins. To implement an effective management plan, nurses and midwives should have a basic understanding of the disease and its various implications for the patients [16].

Evidence suggests that health-related behaviours are affected by knowledge, attitude, and practice (KAP) [17, 18]. However, there are few studies examining the KAP level of HCWSs towards HBV infection in Sudan $[3,15]$. KAP surveys have been widely implemented in public health research and have been reported to be the most commonly used study tools in health-seeking behaviour research [19]. KAP studies have been used to collect information on what the participants know, believe and do in relation to a particular topic [17-20]. The knowledge refers to the understanding of any given topic $[21,22]$. Attitude refers to their feelings towards this subject, preconceived ideas that they may have towards it, intention to a particular behaviour and inclination to react in a certain way to a certain situation [19, 21, 22]. Practice refers to the ways in which they do and demonstrate their knowledge and attitude through their actions [22].

The purpose of this study was to examine the KAP towards HBV infection among nurses and midwives, which could help to inform the strategies for prevention and control of HBV infection in Khartoum, Sudan.

\section{Methods}

\section{Study design and setting}

A descriptive hospital-based cross-sectional study was conducted in Saudi and Saad Abul-Ella hospitals in Khartoum state, Sudan between 18 August and 2 September 2016. These settings were chosen because they are public health, tertiary healthcare facilities providing specialized clinical inpatient and outpatient services for a great number of the Khartoum state population. These two hospitals are popular health facilities specialized in obstetrics and gynaecology services and are main referral hospitals in Khartoum. Khartoum state is the most populous state in Sudan with a population of more than 5 million in the 2008 census. The state has experienced rapid urbanization during the last decades, and the large part of the state's population has reported that their region of origin is outside Khartoum. The state is divided into seven localities. The distribution of public and private hospitals in these localities is made according to the population density.

The total number of nurses and midwives working at the two participating hospitals are 150 (53 nurses and 30 midwives in Saudi hospital, and 57 nurses and 10 midwives in Saad Abul-Ella hospital). The inclusion criteria for this study were nurses and midwives working at these two hospitals with the exclusion of those refusing to participate in the study.

\section{Data collection and analysis}

The study implemented a 31-item structured questionnaire consisting of four sections (Additional file 1) to 
examine the KAP level of nurses and midwives towards HBV infection. The data were collected from HCWs who met eligibility criteria. The structured questionnaire consisted of six questions for the demographic information, 15 questions for knowledge, four questions for attitude, and six questions for practice. When a respondent has no history of needle stick injury, she is supposed to answer three of the practice questions and left the others.

The main purpose of the knowledge questions is to measure the basic knowledge about aetiology, natural history, modes of transmission, complications, and PEP to HBV. The response set of these questions was set as "yes" and "no" choices. Respondents with favourable attitude are those who answered questions which indicated they believe that instruments sterilization, wearing gloves, and vaccination are important to prevent $\mathrm{HBV}$ transmission recommend PEP for those who had been exposed to HBV. The questions regarding practice section aimed to measure whether the participants received HBV vaccine, sterilize instruments, and wear gloves. When the participants had NSI, they were asked whether they used water and soap when they washed their hands, sterilized the wound site, and received PEP. The response set of practice questions was set as "yes" if a participant reported that she performed the practice and "no" if she did not.

A scoring system was generated, and participants were given a score on each correct answer provided. The overall KAP score was determined based on the sum of correct answers to the 15 knowledge-based questions, four attitude-based questions and six practice-based questions (or three practice-based questions if the participant had no history of NSI). A correct response to each question received one point. Median was used to determine the cut-off point for each section of KAP; equal to or more than 12 out of 15 were considered as average knowledge, equal to or more than three out of 4 were considered as favourable attitude, and equal to or more than five out of six were considered as safe practice, and when there is no history of NSI, total of three were considered as safe practice. The questionnaire was constructed based on experts' advice (Department of Community Medicine, Faculty of Medicine, University of Khartoum). The questionnaire was administered to 14 respondents and pretested for its clarity and acceptability, and data from pilot study were not considered in the final analysis. The Statistical Package for Social Sciences (SPSS) software version of 21 was utilized to analyse the data at hand. Descriptive statistics of SPSS provided frequency tables and the distribution of the variables. A Chi-square test was conducted to determine the relationship between the independent categorical variables and the main outcomes of the study (knowledge, attitude, and practice related to HBV infection). The $p$-value of $\leq .05$ was set as the significance level of the study.

\section{Ethical consideration and consent}

The institutional review board of Faculty of Medicine, University of Khartoum granted permission for conducting this research before study initiation, and a permission was also granted by the general directors of $\mathrm{Al} \mathrm{Saud}$ and Saad Abul-Ella hospitals, Khartoum, Sudan. Ethical approval was obtained from the State Ministry of Health in Khartoum state, Sudan. After providing a clear explanation, each respondent's informed written consent was obtained before participation. Confidentiality of the study participants was maintained.

\section{Results}

A total of 110 nurses and midwives from Saudi hospital and Saad Abul-Ella hospital participated in this study with the number of $64(58.2 \%)$ and $46(41.8 \%)$, respectively. Among the 110 participants, 80 (72.7\%) of them were nurses and 30 (27.3\%) of them were midwives. The overall response rate was $73.3 \%$ among the 110 participants. The response rate was $72.7 \%$ among the 80 eligible nurses working at the both hospitals while it was $75 \%$ among the 40 eligible midwives working at the both hospitals. All of the respondents were females with a mean age of $32.9 \pm 11.8$ years. A clear majority of the participants $(80,72.7 \%)$ had an undergraduate degree or above, while 30 participants (27.3\%) had an undergraduate degree. More than half of the participants $(65,59 \%)$ had less than 2 years of work experience and 45 (40.9\%) of them had more than 2 years of work experience. The demographic characteristics of the participants were presented in Table 1.

\section{Assessment of knowledge towards HBV}

Status of knowledge among the respondents was summarized in Table 2. The study findings revealed that the percentage of respondents with average knowledge

Table 1 Demographic characteristics of the respondents in Saudi and Saad Abul-Ella hospitals

\begin{tabular}{llll}
\hline Demographic variables & Number & Percent \% \\
\hline Age Group & 21-30 year & 72 & $65.5 \%$ \\
& 31-40 year & 12 & $10.9 \%$ \\
& 41-50 year & 13 & $11.8 \%$ \\
& More than 50 & 13 & $11.8 \%$ \\
Hospital & Saudi & 64 & $58.2 \%$ \\
& Saad Abul-Ella & 46 & $41.8 \%$ \\
Occupation & Nurse & 80 & $72.7 \%$ \\
\multirow{2}{*}{ Educational level } & Midwife & 30 & $27.3 \%$ \\
& below university & 30 & $27.3 \%$ \\
Experience years & university or above & 80 & $72.7 \%$ \\
& $<2$ years & 65 & $59.1 \%$ \\
& $>2$ years & 45 & $40.9 \%$ \\
\hline
\end{tabular}


Table 2 Knowledge, attitude, and practice of nurses \& midwives regarding HBV infection in Saudi and Saad Abul-Ella hospitals

\begin{tabular}{|c|c|c|}
\hline & Number (correct answer) & Percent (correct answer) \\
\hline \multicolumn{3}{|l|}{ HBV knowledge items } \\
\hline There are several types of hepatitis & 104 & $94.5 \%$ \\
\hline Hepatitis B is a viral infection & 100 & $90.9 \%$ \\
\hline The virus can cause acute hepatitis & 71 & $64.5 \%$ \\
\hline The virus can cause chronic hepatitis & 80 & $72.7 \%$ \\
\hline The virus can cause liver cirrhosis & 91 & $82.7 \%$ \\
\hline The virus can cause hepatocellular carcinoma & 58 & $52.7 \%$ \\
\hline The infection can cause death & 90 & $81.8 \%$ \\
\hline The virus doesn't cause peptic ulcer & 79 & $71.8 \%$ \\
\hline The virus can be transmitted by transfusion of infectious blood. & 105 & $95.5 \%$ \\
\hline The virus can be transmitted by sexual intercourse & 86 & $78.2 \%$ \\
\hline The virus can be transmitted by MTCT. & 83 & $75.5 \%$ \\
\hline The virus isn't transmitted by with all kinds of contact with infected persons. & 71 & $64.5 \%$ \\
\hline The virus can be transmitted by NSI & 96 & $87.3 \%$ \\
\hline The virus is not transmitted through air & 88 & $80.0 \%$ \\
\hline Post-exposure prophylaxis includes IG \& vaccination & 55 & $50.0 \%$ \\
\hline \multicolumn{3}{|l|}{ HBV attitude items } \\
\hline Do you believe that instrument sterilization is important to prevent transmission? & 71 & $64.5 \%$ \\
\hline Do you believe that wearing gloves is important to prevent transmission? & 80 & $72.7 \%$ \\
\hline Do you believe that vaccination could prevent transmission? & 91 & $82.7 \%$ \\
\hline Do you recommend PEP for those who had been exposed to HBV? & 58 & $52.7 \%$ \\
\hline \multicolumn{3}{|l|}{ HBV practice items } \\
\hline They always Sterilize instruments & 99 & $90.0 \%$ \\
\hline They always wear gloves & 100 & $90.9 \%$ \\
\hline Completed the HBV vaccination schedule & 45 & $41.0 \%$ \\
\hline History of NSI & 57 & $51.8 \%$ \\
\hline Washing hands with water \& soap after NSI & 47 & $82.5 \%$ \\
\hline Sterilized the wound site after NSI & 51 & $89.5 \%$ \\
\hline Check if the patient have a blood-borne disease after NSI & 39 & $68.9 \%$ \\
\hline
\end{tabular}

IG immunoglobulins, MTCT mother to child transmission, PEP Post exposure prophylaxis

regarding $\mathrm{HBV}$ is $58.2 \%$. According to study results, HBV was recognized as a viral infection by overwhelming majority of the respondents (90.9\%). The majority of the participants reported that HBV could cause acute and chronic infection with a proportion of 72.7 and $64.5 \%$, respectively. Liver cirrhosis, hepatocellular carcinoma, and death were recognized as possible complications by the participants with a proportion of 82.7, 52.7, and $81.8 \%$, respectively. Knowledge about PEP was average only in half of the respondents (50\%).

\section{Assessment of attitude towards HBV}

The great majority of the respondents $(86.4 \%)$ showed a favourable attitude towards the preventive measures of HBV infection (instruments sterilization, wearing gloves, $\mathrm{HBV}$ vaccination, and PEP). More than half of the participants $(64.5 \%)$ believed that instruments sterilization is important to prevent transmission, and $72.7 \%$ of them think that wearing gloves is important to prevent transmission. A vast majority of the participants (82.7\%) reported that vaccination is an important protective measure. Only $52.7 \%$ of the participants said that they recommend PEP immediately after exposure to infection (Table 2).

\section{Assessment of practice towards HBV}

Among the respondents, $65.5 \%$ of them were considered to have a safe practice regarding HBV infection. According to the study findings, a vast majority of the participants always used sterilized instruments (90\%) and wore gloves (90.9\%). Near half of the participants $(51.8 \%)$ had a history of NSI. Among the participants, washing the 
injury site with water and soap, sterilizing the wound and checking whether the patient has a blood-borne disease were done by $82.5,89.5$ and $68.9 \%$ of the respondents. Only $40.9 \%$ of the respondents had completed the three doses of HBV vaccination, and 27.3\% didn't receive any dose of the vaccine (Table 2).

\section{Association of demographic characteristics and KAP}

The relationship between demographic characteristics and KAP groups is shown in Table 3. Age, occupation, educational degree, and work experience were not significantly associated with knowledge of HBV infection. A significant difference was found between the place of working (hospital) and the level of knowledge of HBV infection $\left(\mathrm{X}^{2}=8.042, p=0.005\right)$.

\section{Discussion}

This study examined the KAP towards HBV among nurses and midwives in two public hospitals specialized in obstetrics and gynaecology services in Khartoum, Sudan. The results of the study showed that 58.2 and $65.5 \%$ of the participants had an average level of knowledge and safe practice, while the majority of the participants had a favourable attitude towards the preventive measures of the HBV infection. These results indicate that there is a need for more HBV health promotion, targeted education, and training of nurses and midwives. Other studies reported that the level of the knowledge of hepatitis is low among different populations, including $\mathrm{HCW}$, in several areas worldwide [23-25].
The findings of the study posited that the level of knowledge was not significantly associated with age, occupation, marital status, educational level, or working experience in this study. Another study conducted among HCWs in White Nile state in Sudan, on the contrary, showed that the level of knowledge was significantly associated with occupation and educational degree [26]. The differences may be attributed to the inclusion of a broader range of professions in the aforementioned study conducted in the White Nile state in Sudan, which considered all HCWs occupations, compared to this study which focused on nurses and midwives. According to findings, workplace (hospital) was the only demographic variable which is associated with the level of knowledge which may be attributed to the differences between these two hospitals. There was a better level of knowledge in Saad Abu-Ella hospital, which is a teaching university hospital, and it is a semiprivate hospital. Other studies have identified several factors associated with the level of knowledge such as sufficiency of the educational programs in the hospital setting, vaccination status, and having family members or friends with active hepatitis [23, 27, 28].

The study findings postulated that half of the participants had a knowledge gap on PEP, which is an effective intervention for prevention of HBV transmission, this fact alerts that the knowledge of PEP for HBV in this study area needs improvement. Also, another striking finding of the study depicted that while near half of the participants have been exposed to HBV risky conditions (51.8\%), the HBV vaccination coverage rate and level of

Table 3 Factors Associated with HBV knowledge attitude and practice

\begin{tabular}{|c|c|c|c|c|c|c|c|}
\hline Demographic variables & No. & Average knowledge & $p$-value & Favourable attitude & $p$-value & Safe practice & $p$-value \\
\hline \multicolumn{8}{|l|}{ Age group } \\
\hline 21-30 year & 72 & $37(51.4 \%)$ & \multirow[t]{4}{*}{0.919} & $31(43.1 \%)$ & \multirow[t]{4}{*}{0.298} & $34(47.2 \%)$ & \multirow[t]{4}{*}{0.576} \\
\hline $31-40$ year & 12 & $6(50.0 \%)$ & & $2(16.7 \%)$ & & 7 (58.3\%) & \\
\hline 41-50 year & 13 & $8(61.5 \%)$ & & $4(30.8 \%)$ & & $6(46.2 \%)$ & \\
\hline More than 50 & 13 & $7(53.8 \%)$ & & $4(30.8 \%)$ & & $4(30.8 \%)$ & \\
\hline \multicolumn{8}{|l|}{ Hospital } \\
\hline Saudi & 64 & $30(46.9 \%)$ & \multirow[t]{2}{*}{0.005} & $58(90.5 \%)$ & \multirow[t]{2}{*}{0.124} & $20(31.4 \%)$ & \multirow[t]{2}{*}{0.391} \\
\hline Saad Abul-Ella & 46 & $34(73.9 \%)$ & & $37(80.4 \%)$ & & 18 (39.1\%) & \\
\hline \multicolumn{8}{|l|}{ Occupation } \\
\hline Nurse & 80 & $48(60.0 \%)$ & \multirow[t]{2}{*}{0.528} & $69(86.3 \%)$ & \multirow[t]{2}{*}{0.955} & $25(31.3 \%)$ & \multirow[t]{2}{*}{0.235} \\
\hline Midwife & 30 & $16(53.3 \%)$ & & $26(86.6 \%)$ & & $13(43.3 \%)$ & \\
\hline \multicolumn{8}{|l|}{ Education } \\
\hline Below university & 30 & $16(53.3 \%)$ & \multirow[t]{2}{*}{0.528} & $24(80.0 \%)$ & \multirow[t]{2}{*}{0.234} & $13(43.3 \%)$ & \multirow[t]{2}{*}{0.235} \\
\hline University or above & 80 & $48(60.0 \%)$ & & $71(88.8 \%)$ & & $25(31.3 \%)$ & \\
\hline \multicolumn{8}{|l|}{ Experience } \\
\hline$<2$ years & 65 & 38 (58.5\%) & \multirow[t]{2}{*}{0.943} & $57(88.7 \%)$ & \multirow[t]{2}{*}{0.626} & 19 (29.2\%) & \multirow[t]{2}{*}{0.159} \\
\hline$>2$ years & 45 & $26(57.8 \%)$ & & 38 (84.4\%) & & $19(42.2 \%)$ & \\
\hline
\end{tabular}


knowledge about PEP were low. Such a situation is alarming and emphasizes the need to increase the level of awareness regarding blood born infections, including HBV infection.

More strategies should be implemented to prevent workplace exposure to reduce the risk of occupational exposure among $\mathrm{HCWs}$ in these, and to improve the level of knowledge and practice of PEP and vaccination coverage in healthcare facilities. In these settings, healthcare organizations should review their preventive strategies, which include written protocols for prompt reporting, evaluation, counselling, and treatment of occupational exposures that might place $\mathrm{HCW}$ s at risk for acquiring the infection and establish these systems if they aren't already in place.

Following procedures should be performed by the healthcare organizations: implementation of standard precautions, availability of HBV vaccination, availability of enough gloves and safety boxes, and access to clinicians who can provide PEP during all working hours $[29,30]$. In addition, HCWs should be trained in the prevention of blood-borne infections, including the need for vaccination against HBV. HCWs should be familiarized with the principles of post exposure management as part of job orientation and on-going job training $[29,30]$.

The findings of the study revealed a high rate of NSI (51\%). Other studies conducted in Sudan, Kenya, Iran, and India revealed similar high NSI rates among HCWs $[3,31-33]$. In developing countries, the severity of such issues tends to be underestimated because many HCWs do not report exposure to hepatitis B virus infection or the risk of exposure. This could compromise appropriate post exposure management [34].

Although a safe and effective vaccine against HBV is available throughout the world, HCWs in developing countries still remain at risk because most of the participants are not vaccinated against HBV [13]. HBV vaccination coverage rates for HCWs range from $18 \%$ in Africa to $77 \%$ in Australia and New Zealand [35]. In this study, HBV vaccination coverage rate was higher than in another study conducted in Ethiopia where the vaccination schedule has been recently completed (5.4\%) [36]. That study conducted in Ethiopia reported that low vaccination status was explained by non-availability of the vaccines and the cost issues [36]. Other alternative preventive measures such as wearing gloves and hand hygiene are simple and cost-effective; however, still require staff accountability and behavioural change.

The findings of this study need to be considered in the context of some limitations; this is a cross-sectional study done in two sites, which might limit results generalization for all settings in the country. Further analysis is needed to investigate risk factors that influence KAP level of HCWs towards HBV infections.

\section{Conclusion}

It can be concluded that most of the nurses and midwives working at Saudi and Saad Abul-Eleella hospitals are aware of HBV infection. However, a significant proportion of the participants lack the necessary knowledge about post exposure management and prevention of occupational exposures. The study reveals a low level of HBV vaccination coverage rate and high rate of NSI. Further strategies for preventing workplace exposure, training programs on $\mathrm{HBV}$ infection, including PEP, and increasing vaccination coverage rate of all HCWS are highly recommended.

\section{Supplementary information}

Supplementary information accompanies this paper at https://doi.org/10. 1186/s12889-019-7982-8

Additional file 1. Interview guide: the structured questionnaire used for this study.

\section{Abbreviations}

HBsAg: Hepatitis B surface antigen; HBV: Hepatitis B virus; HCWS: Healthcare workers; IG: Immunoglobulins; KAP: Knowledge, attitude and practice; MTCT: Mother to child transmission; NSI: Needle stick injury; PEP: Post exposure prophylaxis

\section{Acknowledgements}

Dr. El-Fatih Malik (Director General, Planning and international health directorate, Federal Ministry of Health, Sudan) is greatly acknowledged for his valuable notes.

\section{Authors' contributions}

(SMM) Involved in the conception of the research idea, study design, questionnaire development and data collection; (SMM, SOM) analyzed data, interpreted the results and drafted the manuscript. Both authors revised and approved the final manuscript.

\section{Funding}

No fund.

\section{Availability of data and materials}

The datasets used during the current study are available from the corresponding author on reasonable request.

\section{Ethics approval and consent to participate}

Permission for conducting this research was granted by the institutional review board, University of Khartoum faculty of Medicine prior to study initiation, and from general directors of Al Saud and Saad Abul-Ella hospitals, Khartoum, Sudan. Ethical approval was obtained from the State Ministry of Health in Khartoum state, Sudan. Each respondent's written consent was obtained prior to participation.

\section{Consent for publication}

Not applicable.

\section{Competing interests}

The authors declare that they have no competing interests.

Received: 28 November 2018 Accepted: 21 November 2019 Published online: 29 November 2019

References

1. Badawi MM, Atif MS, Mustafa YY. Systematic review and meta-analysis of HIV, HBV and HCV infection prevalence in Sudan. Virol J. 2018;15:1-16.

2. Mudawi $\mathrm{H}$. Epidemiology of viral hepatitis in Sudan. Clin Exp Gastroenterol. 2008;1:9-14. 
3. Elduma A, Saeed N. Hepatitis B virus infection among staff in three hospitals in Khartoum, Sudan, 2006-07. East Mediterr Health J. 2011;17(06):474-8.

4. Puri P. Tackling the Hepatitis B disease burden in India. J Clin Exp Hepatol. 2014;4(4):312-9

5. Yousif M, Mudawi H, Bakhiet S, Glebe D, Kramvis A. Molecular characterization of hepatitis B virus in liver disease patients and asymptomatic carriers of the virus in Sudan; 2013.

6. Ott JJ, Stevens GA, Groeger J, Wiersma ST. Global epidemiology of hepatitis $B$ virus infection: new estimates of age-specific HBsAg seroprevalence and endemicity. Vaccine. 2012;30:2212-9. https://doi.org/10.1016/j.vaccine.2011. 12.116.

7. Abdo A, Mohammed D, Satti M. Prevalence of Hepatitis B virus among blood donors and assessment of blood donor' $s$ knowledge about HBV in Sudan. HIV/AIDS Res Treat Open J. 2015;2(3):76-80.

8. Elmukashfi TA, Ibrahim OA, Elkhidir IM. Socio-demographic characteristics of health care workers and Hepatitis B virus (HBV) infection in public teaching hospitals in Khartoum state, Sudan. Glob J Health Sci. 2012;4(4):37-41.

9. Abdalla M, Abou A, Eltahir YM, Ali AS. Seroprevalence of Hepatitis B virus and Hepatitis C virus among blood donors in Nyala, South Dar Fur, Sudan. Virol J. 2009;6:146. https://doi.org/10.1186/1743-422X-6-146.

10. Dunkelberg JC, Berkley EMF, Thiel KW, Leslie KK. Hepatitis B and C in pregnancy: a review and recommendations for care. J Perinatol. 2014;34(12): 882-91. https://doi.org/10.1038/jp.2014.167.

11. Tram T. Hepatitis B in pregnancy. Clin Infect Dis. 2016;62(Suppl 4):S314-7.

12. Chang MS, Tuomala R, Rutherford AE, Mutinga ML, Andersson KL, et al. Postpartum care for mothers diagnosed with hepatitis B during pregnancy. Am J Obstet Gynecol. 2015;212(3):365.e1-7. https://doi.org/10.1016/j.ajog. 2014.09.032.

13. Olivier H, Tatsilong P, Noubiap JJN, Nansseu JRN, Aminde LN, Bigna JJR, et al. Hepatitis B infection awareness, vaccine perceptions and uptake, and serological profile of a group of health care workers in Yaoundé, Cameroon. BMC Public Health. 2016;16:706. https://doi.org/10.1186/s12889-016-3388-z.

14. Elseviers MM, Arias-Guillén M, Gorke A, Arens HJ. Sharps injuries among the health care workers : review of incidence, transmissions and costs. J Ren Care. 2014;40(3):150-6.

15. Siddig A, Mustafa M, Mohamed AS, Ahmed T, Alamin A, Hassanahmed MT, et al. Knowledge, Attitude and Practice of Hepatitis (B) among Healthcare Workers in Relation to their Vaccination Status in Khartoum, Sudan, 2015: A Cross-sectional Study. Sudan J Med Sci. 2018;13(1):22-214. https://doi.org/ 10.18502/sims.v13i1.16862018.

16. Boehme TL. Hepatitis B. The Nurse-Midwife's Role in Management and Prevention. J Nurse Midwifery. 1985;30:79-87.

17. Klett-tammen CJ, Krause G, Seefeld L, Ott JJ. Determinants of tetanus, pneumococcal and influenza vaccination in the elderly: a representative cross-sectional study on knowledge, attitude and practice (KAP). BMC Public Health. 2016:1-9. https://doi.org/10.1186/s12889-016-2784-8.

18. Higuera-Mendieta DR, Cortés-Corrales S, Quintero J, González-Uribe C. KAP Surveys and Dengue Control in Colombia: Disentangling the Effect of Sociodemographic Factors Using Multiple Correspondence Analysis. PLoS Negl Trop Dis. 2016;10(9):e0005016. https://doi.org/10.1371/journal.pntd. 0005016.

19. Haq N, Hassali MA, Shafie AA, Saleem F, Farooqui M, Haseeb A, et al. A cross-sectional assessment of knowledge, attitude and practice among Hepatitis-B patients in Quetta, Pakistan. BMC Public Health. 2013;13:448.

20. WHO. Advocacy, communication and social mobilization for TB control: a guide to developing knowledge, attitude and practice surveys. Geneva; 2008. Available from: https://apps.who.int/iris/bitstream/handle/10665/43 790/9789241596176_eng.pdfijsessionid=9D52C9E7A72AEA6496 BDEA70B9D7E853? sequence $=1$

21. Kaliyaperumal K. Guideline for conducting a knowledge, attitude and practice (KAP) study. Commun Ophthalmol. 2004;4(1):7-9.

22. Badran IG. Knowledge, attitude and practice the three pillars of excellence and wisdom: a place in the medical profession. East Mediterr Health J. 1995; 1:8-16.

23. Ahmad A, Sann LM, Rahman HA. Factors associated with knowledge, attitude and practice related to hepatitis $B$ and $C$ among international students of Universiti Putra Malaysia. BMC Public Health. 2016;16:611. https://doi.org/10.1186/s12889-016-3188-5.

24. Chao J, Chang ET, So SK. Hepatitis B and liver cancer knowledge and practices among healthcare and public health professionals in China: a cross-sectional study. BMC Public Health. 2010;10:98.
25. Ataei B, Meidani M, Khosravi M, Khorvash F, Akbari M. Knowledge, attitude, and performance of medical staff of teaching healthcare settings about hepatitis B and C in Isfahan, Iran. Adv Biomed Res. 2014;3:267. https://doi. org/10.4103/2277-9175.148249.

26. Elsheikh TA, Balla SA, Abdalla AA, Elgasim MA, Swareldahab Z, Bashir AA. Knowledge, Attitude and Practice of Heath Care Workers Regarding Transmission and Prevention of Hepatitis B Virus Infection, White Nile State, Sudan, 2013. Am J Health Res. 2016;4(2):18-22.

27. Brouard C, Gautier A, Saboni L, Jestin C, Semaille C, Beltzer N. Hepatitis B knowledge, perceptions and practices in the French general population: the room for improvement. BMC Public Health. 2013;13:576.

28. Joukar F, Mansour-Ghanaei F, Naghipour MR, Hasandokht T. Nurses' Knowledge toward Hepatitis B and Hepatitis C in Guilan, Iran. Open Nurs J. 2017;11:34-42. https://doi.org/10.2174/1874434601711010034.

29. Centres for Disease Control and Prevention (CDC). Updated US public health services for the management of occupational exposure to HBV, HCV and HIV and Recommendations for Postexposure Prophylaxis. Infect Dis Clin Pract. 2001;10(6):338-40.

30. Arafa AE, Mohamed AA, Anwar MM. Nurses' knowledge and practice of blood-borne pathogens and infection control measures in selected BeniSuef hospitals Egypt. J Egypt Public Health. 2016;91:120-6. https://doi.org/ 10.1097/01.EPX.0000491268.30015.ce.

31. Mbaisi EM, Wanzala P, Omolo J. Prevalence and factors associated with percutaneous injuries and splash exposures among health-care workers in a provincial hospital, Kenya, 2010. Pan Afr Med J. 2013;14:10. https://doi.org/ 10.11604/pami.2013.14.10.1373.

32. Mohammadi N, Allami A, Malek Mohamadi R. Percutaneous exposure incidents in nurses: knowledge, practice and exposure to hepatitis B. Hepat Mon. 2011;11(3):186-90.

33. Jain M, Sabharwal ER, Srivastava D. Practices of Health Care Personnel Regarding Occupational Exposure. J Clin Diagn Res. 2016;10(11):DC14-7. https://doi.org/10.7860/JCDR/2016/20934.8893.

34. Konlan KD, Aarah-Bapuah M, Kombat JM, Wuffele GM. TOPIC: "The level of nurses' knowledge on occupational post exposure to hepatitis B infection in the Tamale metropolis, Ghana". BMC Health Serv Res. 2017;17:254. https:// doi.org/10.1186/s12913-017-2182-7.

35. Singhal V, Bora D, Singh S. Hepatitis B in health care workers: Indian scenario. J Lab Physicians. 2009;1(2):41-8. https://doi.org/10.4103/0974-2727. 59697.

36. Abeje G, Azage M. Hepatitis B vaccine knowledge and vaccination status among health care workers of Bahir Dar City Administration, Northwest Ethiopia: a cross sectional study. BMC Infect Dis. 2015;15(1):1-6.

\section{Publisher's Note}

Springer Nature remains neutral with regard to jurisdictional claims in published maps and institutional affiliations.
Ready to submit your research? Choose BMC and benefit from:
- fast, convenient online submission
- thorough peer review by experienced researchers in your field
- rapid publication on acceptance
- support for research data, including large and complex data types
- gold Open Access which fosters wider collaboration and increased citations
- maximum visibility for your research: over $100 \mathrm{M}$ website views per year
At BMC, research is always in progress.
Learn more biomedcentral.com/submissions 